\title{
Sulfa Allergy and Therapeutic Decisions
}

\author{
Kristen K Fuhrmann, PharmD, Nat Dumrongmongcolgul, MD
}

\section{CASE}

A 71-year-old man with a history of "sulfa" allergy and congestive heart failure presented with shortness of breath secondary to pulmonary edema. Which diuretics can be used in his treatment?

\section{Discussion}

True allergic responses to drugs occur in $5 \%$ of the population and in up to $30 \%$ of HIV infected patients. ${ }^{1}$ Patients often describe any adverse drug reaction as an allergy, and sulfonamide or "sulfa" allergy is one of the most commonly reported allergies. Sulfonamide is a chemical structure contained in many groups of medications, including antibiotics, diuretics, and nonsteroidal anti-inflammatory drugs. ${ }^{1}$ Allergic or hypersensitivity reactions to sulfonamide medications can cause multiple symptoms and/or syndromes; the most common presentation is either a generalized maculopapular rash or a fixed drug eruption. The mechanisms include both immune and nonimmune reactions. ${ }^{1}$ Common nonimmune reactions include drug intolerances, idiosyncratic reactions, and toxic reactions. In general the presence of fever implies a more severe reaction. ${ }^{1}$

\section{Classification of REActions}

- Type I or IgE mediated reactions usually occur within 30 minutes after exposure and can cause angioedema, urticaria, hives, bronchospasm, and/or cardiovascular collapse.

- Type II or cytotoxic reactions usually take 7-14 days to develop. Clinical presentations include hemolytic anemia and vasculitis. ${ }^{2}$

- Type III or immune complex reactions develop over several days to weeks and can involve multiple organs. This clinical syndrome includes fever, malaise, lymph

$$
\begin{aligned}
& \text { Corresponding author: Kristen K Fuhrmann, } \\
& \text { PharmD } \\
& \text { Contact Information: kristen.fuhrmann@umc- } \\
& \text { healthsystem.com } \\
& \text { DOI: 10.12746/swrccc2013.0101.006 }
\end{aligned}
$$

adenopathy, urticarial rash, arthralgias, and other organ involvement, such as the kidneys, lungs, and liver. ${ }^{1}$

- Type IV or delayed type hypersensitivity reactions typically require $48-72$ hours to develop and represent a $\mathrm{T}$ cell-mediated reaction. Presentations include Stevens-Johnson syndrome and toxic epidermal necrolysis. Delayed hypersensitivity may cause fixed drug eruptions, but the mechanism is uncertain. These occur within $0.5-8$ hours after exposure. The initial edematous lesions develop into well-delineated, round, dark, reddish-purple papules. They often recur at the same area with re-exposure and usually resolve after discontinuation of the drug. ${ }^{3}$

\section{Pathogenesis}

Sulfonamide-containing medications can be divided into two distinct categories, antibiotics and non-antibiotics. ${ }^{4}$ The antibiotic group includes the sulfonarylamine antibiotics, such as sulfanilamide, sulfoxazole, and sulfamylon. 1,4,5,6 These antibiotics are structurally related with the sulfonamide moiety directly connected to a benzene ring, an amine $\left(-\mathrm{NH}_{2}\right)$ structure at the N4 position, and an aromatic ring at the N1 position. 1,5,6,7 It is a metabolite of the sulfonarylamines that is antigenic and elicits T-cell and IgE immunemediated reactions. 1,5,6 The second class, non-sulfonarylamines or sulfonamide non-antibiotics, include the carbonic anhydrase inhibitors, sulfonylureas, loop diuretics, thiazide diuretics, COX-2 inhibitors, and protease inhibitors. These non-sulfonarylamines lack the amine structure at the N4 position. ${ }^{1,5,6,7}$ A subgroup of the non-antibiotics are simply sulfonamide containing and include sumatriptan, topiramate, zonisamide, ibutilide, sotalol, dapsone and probenecid. This group contains a sulfonamide moiety not directly connected to the benzene ring. ${ }^{7}$ Although these non-antibiotic drugs contain the sulfonamide moiety $\left(-\mathrm{SO}_{2} \mathrm{NH}_{2}\right)$ similar to the sulfonylarylamine antibiotics, the lack of the amine substituent at the N4 position reduces the likelihood of a potential cross reaction in patients with a documented "sulfonamide allergy". 1,5,7 


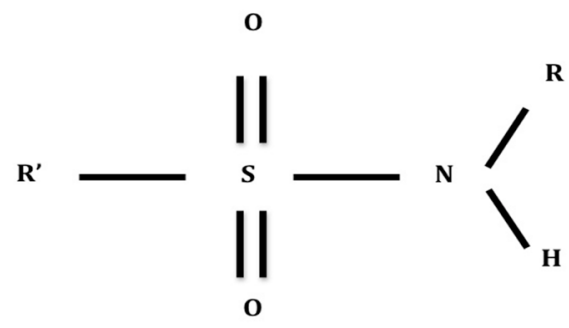

Sulfonamide

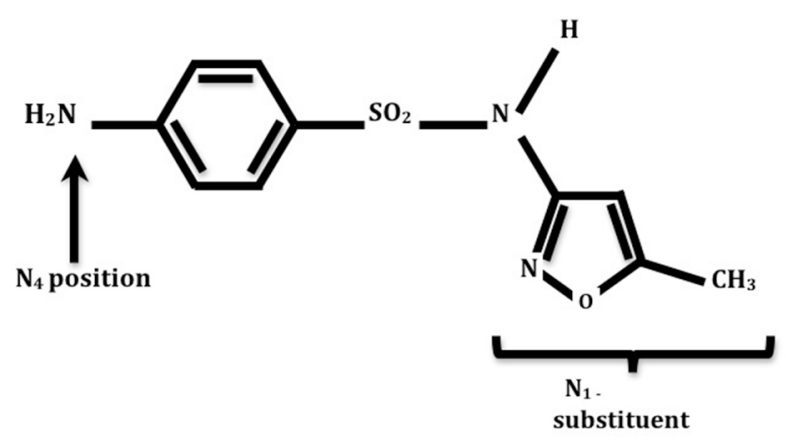

Sulfamethoxazole

These structural similarities have led to confusion among clinicians and may unnecessarily result in therapeutic limitations in patients with a documented "sulfa" or "sulfonamide allergy". Package inserts and pharmacological databases for sulfonamide-derived agents contain many cautionary statements, warnings, and contraindications against their use in patients with sulfonamide allergy. 1,7 While there are case reports that appear to support cross reactivity, closer examination coupled with the results of the most relevant study to date by Strom and colleagues support the conclusion that cross reactivity is absent and unlikely with non-antibiotic sulfonamides. ${ }^{2,7}$ In a review of sulfonamide antibiotic-allergic patients, the incidence of concurrent penicillin allergy was higher than the incidence of reaction to non-antibiotic sulfonamides. ${ }^{8}$ Moreover, the incidence of reactions to sulfonamide non-antibiotics was higher in those who were also penicillin-allergic than in those who were sulfonamide-antibiotic allergic alone (15\% vs. $10 \%))^{1,8}$ It has been reported that the likelihood of reaction is higher in patients with multiple drug allergies as they appear to have a predisposition to allergic and adverse reactions. ${ }^{3,7}$ Therefore, it is important for clinicians to obtain a thorough history of the reaction in hypersensitive patients who report multiple drug al- lergies as they are at an increased risk of adverse reactions. ${ }^{1,3,5,6,7}$ There is also a concern about reactions to medications such as dapsone that are not sulfonamide antibiotics but share a similar structure in the N4 arylamine portion. So far there is no evidence to support cross reactions between drugs that share N4 arylamine portion and sulfonamide antibiotics.

\section{Case conclusion}

Our patient could not provide a clear description of a drug reaction to "sulfa." Clinicians need to obtain a detailed history to clarify possible drug allergies to determine the exact drug and the reaction. If he does not have an allergy to furosemide, there should be no reason not to use it if indicated. Even if our patient did have an allergic reaction to a sulfonamide antibiotic, cross reactivity to furosemide is very unlikely. Patients who have had a severe reaction to any medication should be monitored closely when a new drug is started, and the possibility of anaphylaxis should be considered.

\section{KEY POINTS}

1. The term sulfa allergy is commonly used to refer to any kind of adverse reaction to sulfonamidecontaining medications. The clinician/pharmacist needs to identify the exact medication and the exact reaction. In particular, antibiotic sulfonamides should be differentiated from sulfonylureas, diuretics, and other nonantibiotic drugs.

2. Current evidence does not support a restriction in the use of non-antibiotic sulfonamide medications in sulfonamide antibiotic-allergic patients. If a sulfonamide containing medication is therapeutically necessary, then it is prudent to assume that non-antibiotic sulfonamides are safe and cross reactivity is unlikely.

3. Patients with documented anaphylaxis with sulfonamides, or other serious drug reactions, and/ or multiple medication allergies should avoid sulfonamide containing drugs and structurally related compounds. 
INDEX TERMS- sulfonamides, antibacterial agents/ adverse reactions, drug allergy, drug hypersensitivity

Author Affiliation: Kristen Fuhrmann is a pharmacist at University Medical Center in Lubbock. Nat Dumrongmongcol gul is a resident in Internal Medicine at TTUHSC.

Received: $11 / 10 / 2012$

Accepted: $12 / 7 / 2012$

Reviewers: Charles Seifert, PharmD; Zachary Mulkey, MD

Published electronically: 1/2/2013

Conflict of Interest Disclosures: None

\section{REFERENCES}

1. Brackett CC, Singh H, Block JH. Likelihood and mechanisms of cross-allergenicity between sulfonamide antibiotics and other drugs containing a sulfonamide functional group. Pharmacotherapy 2004; 24: 856-870.

2. Klinker KP, Harbilas JW, Johns TE. Drug-induced hematologic disorders. In: DiPiro J, Talbert R, Yee G, Matzke G, Wells B, Posey LM, eds. Pharmacotherapy: a pathophysiologic approach, 5th ed. New York: McGraw-Hill, 2002:1783-95.

3. Leyva L, Torres MJ, Posadas S, et al. Anticonvulsant-induced toxic epidermal necrolysis: monitoring the immunologic response. J Allergy Clin Immunol 2000; 105:157-65

4. Kelly TE, Hackett PH. Acetazolamide and sulfonamide allergy; a not so simple story. High Altitude Med Biol 2010; 11:319-322.

5. Castrejon L, Lavergne SN, El-Sheikh, et al. Metabolic and chemical origins of cross-reactive immunological reactions to arylamine benzenesulfonamides: $\mathrm{T}$ cell responses to hydroxylamine and nitroso derivatives. Chem Res Toxicol 2010; 23:184-192.

6. Castrejon J.L., Berry N, El-Gaiesh S, et al. Stimulation of human $\mathrm{T}$ cells with sulfonamides and sulfonamides metabolites. J allergy Clin Immunol 2010; 125:411-418.

7. Johnson KK, Green DL, Rife JP, et al. Sulfonamide cross-reactivity: fact or fiction. Ann Pharmacotherapy 2005; 39:290-301.

8. www.lexicomponline.com, accessed 11.7.12. 